\title{
MicroRNA-9 Inhibits NLRP3 Inflammasome Activation in Human Atherosclerosis Inflammation Cell Models through the JAK1/STAT Signaling Pathway
}

\author{
Yue Wanga Zhihua Han ${ }^{\mathrm{a}}$ Yuqi Fan ${ }^{\mathrm{a}}$ Junfeng Zhang ${ }^{\mathrm{a}}$ Kan Chen ${ }^{\mathrm{a}}$ Lin Gao \\ Huasu Zeng ${ }^{\mathrm{a}}$ Jiatian Cao ${ }^{\mathrm{a}, \mathrm{b}}$ Changqian Wang ${ }^{\mathrm{a}}$ \\ aDepartment of Cardiology, No. 9 People's Hospital, School of Medicine, Shanghai Jiao Tong University, \\ bDepartment of Cardiology, Shanghai Institute of Cardiovascular Diseases, Zhongshan Hospital, Fudan \\ University, Shangai, China
}

\section{Key Words}

miR-9 • NLRP3 inflammasome $•$ JAK1 1 STAT1 $・$ Atherosclerosis

\begin{abstract}
Background/Aims: MicroRNA-9 (miR-9) is involved in inflammatory reaction in atherosclerosis; however, its function and regulatory mechanisms remain unclear. We aimed to uncover the exact roles of miR-9 and downstream signaling pathways using in vitro human atherosclerosis models. Methods: We used oxidized low-density lipoprotein (oxLDL)-stimulated human THP1 derived macrophages, oxLDL-stimulated human primary peripheral blood monocytes and lipopolysaccharides (LPS) or Alum-stimulated human THP-1 derived macrophages as in vitro atherosclerosis inflammation models. Transient transfection of over-expression vectors, small interference RNAs (siRNAs) or antisense oligonucleotides was used to regulate intracellular protein or miR-9 levels. Cell responses and signal transduction were detected by multiple assays including Western blotting, enzyme-linked immunosorbent assay (ELISA) and luciferase reporter assay. Results: MiR-9 inhibited while anti-miR-9 antisense oligonucleotides induced interleukin-1 beta (IL-1 $\beta$ ) and NLRP3 inflammasome activation in all in vitro models. Janus kinase 1 (JAK1) and matrix metalloproteinase 13 (MMP-13) were identified as the target genes of miR-9. In oxLDL-stimulated human THP-1 derived macrophages, knockdown of JAK1 by siRNA blocked the phosphorylation of signal transducer and activator of transcription 1 (STAT1) and mimicked the effects of miR-9. In the same model, JAK1 knockdown blocked the phosphorylation of NF-KB p65 in the nuclei and the phosphorylation of NF-KB IKB $\alpha$ in the cytoplasm. Conclusions: Our study demonstrated that miR-9 could inhibit activation of the NLRP3 inflammasome and attenuate atherosclerosis-related inflammation, likely through the JAK1/STAT1 signaling pathway. Therefore, miR-9 may serve as a potential therapeutic target for atherosclerosis.
\end{abstract}




\section{Introduction}

Atherosclerosis is one of the leading causes of death in vascular diseases. Although the etiopathogenesis is not completely clear, atherosclerosis has been recognized as a complex chronic inflammatory disease, in which continuous dyslipidemia and inflammation play a vital role [1,2]. Atherosclerosis-related inflammation is elicited by atherogenic lipid mediators, especially oxLDL. Upon oxLDL stimulation, monocytes from peripheral blood migrate to the subendothelial space, where they differentiate into macrophages. Activated macrophages secrete various proinflammatory mediators, including interferon $\gamma$ (IFN- $\gamma$ ), interleukins (IL), and proteases, leading to the inflammatory cascade and contributing to unlimited lipid uptake, foam cell formation and progression of atherosclerosis[3-6].

The NLRP3 inflammasome was identified as a novel link between cholesterol metabolism and inflammation [7, 8]. It belongs to the nucleotide oligomerization domain (NOD)-like receptors (NLRs) family, which has been closely implicated in the pathogenesis of several chronic inflammatory diseases, including atherosclerosis, gout, and type 2 diabetes [9]. The NLRP3 receptor responds to numerous diverse exogenous and endogenous ligands, including bacteria [10], extracellular ATP [11], amyloid- $\beta$ [12], uric acid[13], and cholesterol crystals[7]. In a recent study, oxLDL has also been proved to activate the NLRP3 inflammasome [14]. Once activated, NLRP3 receptor recruits the adaptor protein ASC (apoptosis-associated speck like protein containing a caspase-recruitment domain) and procaspase- 1 to form an active NLRP3 inflammasome complex [15], which results in caspase-1 activation and subsequent cleavage of IL-1 $\beta$ and IL-18 into their active forms. Recently, inhibition of the NLRP3 inflammasome has been shown to protect against atherosclerosis [16, 17]. However, its mechanisms and related signaling pathways have not been clarified.

MicroRNAs (miRNAs) are a family of small noncoding RNAs with 20-25 nucleotides, which function through binding to their complementary sites on the 3'-UTR of target mRNAs to mediate mRNA degradation and translation repression [18]. MiRNAs function in various biological and pathological processes, including atherosclerosis and inflammation[19-22]. Previous report indicated that microRNAs played a key role in macrophage biology by regulating their differentiation from precursor cells and modulating the expression of inflammatory mediators and signaling pathways [23]. We also found that several miRNAs were highly expressed in human peripheral blood monocytes stimulated with oxLDL [24]. Among them, miR-146a and miR-155 have been reported to regulate atherosclerosisrelated inflammation [25]. However, whether and how miR-9 regulates inflammation in atherosclerosis is still unknown. In this study, we aimed to investigate the effects and mechanisms of miR-9 on the NLRP3 inflammasome in oxLDL-stimulated human THP-1 derived macrophages and human primary monocytes from peripheral blood.

\section{Materials and Methods}

\section{Cell culture}

Human monocytic cell line THP-1 (American Type Culture Collection, Bethesda, MD, USA) was cultured in RPMI 1640 medium (Gibco, NY, USA) supplemented with 10\% fetal bovine serum (FBS),10 $\mathrm{mmol} / \mathrm{L}$ HEPES (Sigma, St Louis, MO, USA) and $100 \mathrm{U} / \mathrm{mL}$ penicillin-streptomycin (Sigma). To induce the differentiation of monocytes into macrophages, we cultured human THP-1 cells in $100 \mathrm{nmol} / \mathrm{L}$ phorbol12myristate 13-acetate (Calbiochem, San Diego, CA, USA) for $48 \mathrm{~h}$. The culture medium was then changed into RPMI1640 medium containing $0.5 \%$ FBS for a $6 \mathrm{~h}$ starvation $[26,27]$. For NLRP3 inflammasome stimulation, human THP-1 derived macrophages were treated with $50 \mu \mathrm{g} / \mathrm{mL}$ oxLDL for $24 \mathrm{~h}(4 \mathrm{~h}$ for STAT1 signaling experiments), $100 \mathrm{ng} / \mathrm{mL}$ LPS (Escherichia coli serotype 0111:B4, Sigma) for $24 \mathrm{~h}$ or $130 \mu \mathrm{g} / \mathrm{mL}$ Aluminium Hydrogel (Alum, from Sigma) for $4 \mathrm{~h}$ [28, 29].

Peripheral human blood was obtained from healthy donors. This study conformed to the principles outlined in the Declaration of Helsinki for use of human blood and was approved by the Ethics Committee of Experimental Research, Medical College, Shanghai Jiaotong University. Human primary peripheral 


\section{Cellular Physiology Cell Physiol Biochem 2017;41:1555-1571 \\ \begin{tabular}{l|l|l} 
and Biochemistry & $\begin{array}{l}\text { DOI: 10.1159/000470822 } \\
\text { Published } 2017 \text { The Author(s). Published by S. Karger AG, Basel }\end{array}$ & $\begin{array}{l}\text { C) } 2017 \text {. Tharch 27, } 2017 \\
\text { www.karger.com/cpb }\end{array}$
\end{tabular}}

Wang et al.: MicroRNA-9 Inhibits NLRP3 Inflammasome Activation

blood monocytes were prepared as previously described [24]. Briefly, peripheral blood mononuclear cells (PBMCs) were isolated by Ficoll-isopaque (Sigma) density gradient. PBMCs were seeded in six-well plates using RPMI1640 medium containing 5\% autologous serum. After $2 \mathrm{~h}$ incubation in $5 \% \mathrm{CO}_{2}$ at $37^{\circ} \mathrm{C}$, nonadherent cells in medium were carefully removed and attached cells were human primary peripheral blood monocytes. Human primary peripheral blood monocytes were stimulated with $100 \mathrm{ng} / \mathrm{mL}$ LPS for $24 \mathrm{~h}$.

Transfection of miR-9 precursor and inhibitor

MiR-9 precursor (pre-miR-9) or miR-9 inhibitor (anti-miR-9) (Ambion) was transfected into human THP-1 derived macrophages and human primary peripheral blood monocytes using the fast transfection protocol recommended by Qiagen (USA). The miR-9 precursor or inhibitor was diluted in the medium to a final concentration of $50 \mathrm{nM}$. To confirm the efficiency of transfection, the same amount of Cy3-labelled negative control (Ambion) was also transfected. Six hours after transfection, the cells were exposed to oxLDL (50 $\mu \mathrm{g} / \mathrm{mL}$ ) for another $24 \mathrm{~h}$ and then harvested for further experiments.

\section{Real-time PCR}

Total RNA was isolated using Trizol reagent (Invitrogen, Carlsbad, CA, USA) according to the manufacturer's instruction. RNA was reversely transcribed using GoTaq ${ }^{\circledR}$ 2-Step RT-qPCR System (Promega, Madison, WI, USA) [30]. Real-time PCR was performed in triplicates using a Roche LightCycler 480 system. $\beta$-actin was used as an endogenous control. The primers for $I L-1 \beta, N L R P 3$, JAK1, MMP13 and $\beta$-actin were designed and synthesized by Sangon Biotech, Shanghai, China. The sequences are in Table 1.

\section{Western blotting assays}

Cell culture medium was concentrated using Vivaspin 6 centrifugal concentrator with a 5 kDa cut-off (Sartorius), after which immunoblot analysis was performed. Protein isolation and Western bolt analysis of cell lysates were performed as described previously [11]. Briefly, protein extracts were prepared and protein concentrations were measured using the bicinchoninic acid (BCA) protein assay (Pierce, Rockford, IL, USA). After denaturation, the solubilized proteins $(20 \mu \mathrm{g})$ were subjected to electrophoresis on $10 \%$ polyacrylamide sodium dodecyl sulphate gels and subsequently transferred onto polyvinylidene difluoride membranes (Millipore, Billerica, MA, USA). The membranes were then probed with primary antibodies for IL-1 $\beta$, pro-IL-1 $\beta$, pro-caspase-1, JAK1, MMP-13, and caspase-1 (all from R\&D Systems), NLRP3, phospho-p65, IкB $\alpha$, phospho-STAT1, total STAT1, lamin B, and $\beta$-actin (all from Cell Signaling Technology). Secondary goat anti-rabbit or goat-anti-mouse antibodies labeled with far-red fluorescent Alexa Fluor 680 dye were used. Signal detection was performed by Odyssey (Li-cor, USA) [24]. Quantity One (Bio-Rad) was used for scanning and densitometric analysis.

Nuclear and cytoplasmic protein fractionation was performed with the Nuclear/Cytoplasmic Protein Extraction Kit (Beyotime, China) according to the manufacturer's instructions.

To detect the protein level of secreted IL-1 $\beta$, human THP-1 derived macrophages or human primary peripheral blood monocytes were stimulated, as described, but in the absence of FCS. Cell culture supernatants were harvested and concentrated 10 folds with Ultracel $10 \mathrm{~K}$ Amicon Ultra centrifugal filters (Merck Millipore, Darmstadt, Germany) [31].

Table 1. Primers used for Real-time PCR

\begin{tabular}{cll}
\hline IL-1 $\beta[21]$ & Forward & TTCAACACGCAGGACAGGTACAG \\
Reverse & CCAGGGACAGGATATGGAGCA \\
NLRP3 [21] & $\begin{array}{l}\text { Forward } \\
\text { Reverse }\end{array}$ & AGCCAAGAATCCACAGTGTAACC \\
& Forward & GGTCAGCATTAACAAGCAGGACAA \\
JAK1 & Reverse & AGCCATCTACCAGGGACACAAAG \\
MMP-13 & Forward & CCCTTGATGCCATTACCAGTC \\
& Reverse & TCCGCATCAACCTGCTGAG \\
\hline
\end{tabular}




\section{Cellular Physiology Cell Physiol Biochem 2017;41:1555-1571

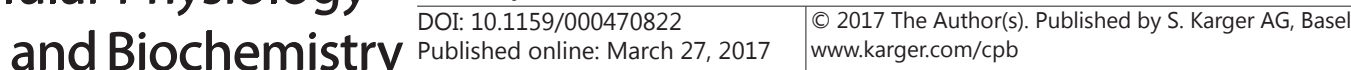

Enzyme-linked immunosorbent assay

IL-1 $\beta$, TGF- $\beta 1$, MCP-1, and IL-10 ELISA assay kits were purchased from R\&D Systems. The concentrations of the secreted IL-1 $\beta$, TGF- $\beta 1$, MCP-1, and IL-10 in the human THP- 1 derived macrophage or human primary peripheral blood monocyte culture medium were assessed according to the manufacturer's instructions.

DNA construct and luciferase report assay

For luciferase reporter experiments, the 3'UTR of JAK1 and MMP-13 was amplified by PCR from human genomic DNA and cloned into the psiCHECKTM-2 firefly luciferase vector (Promega) between the Not 1 and $S g f 1$ sites. The construct with mutated targeting fragment at the 3'UTR of JAK1 or MMP-13 without the putative miR-9 binding sequence was used as a negative control. The mutant form was synthesized and inserted into the psiCHECKTM-2 firefly luciferase vector. Human THP-1 derived macrophages were seeded into 24-well plates and transfected by using Lipofectamine 2000 according to the manufacturer's protocol (Invitrogen). Cells treated with $10 \mathrm{nM}$ pre-miR-9 or pre-negative control (pre-NC), or with $10 \mathrm{nM}$ antimiR-9 or anti-negative control (anti-NC) (Ambion) were transfected with $0.1 \mu \mathrm{g}$ of JAK1 or MMP-13 3'UTR firefly luciferase report vector and $0.02 \mu \mathrm{gp}$ RL-TK Renilla luciferase vector (Promega) for normalization of transfection. After $48 \mathrm{~h}$, cells were washed and lysed by the lysis buffer, and firefly and renilla luciferase activity was determined using the dual-luciferase reporter assay system and a luminometer (Promega) as described previously [32]. Relative reporter activity was obtained by normalizing the firefly luciferase activity to the internal control renilla luciferase activity.

\section{SiRNA}

JAK1 small interference RNA (siRNAs) and siRNA negative control non-silencing siRNA were procured from Genepharma (Shanghai, China). Three individually designed siRNAs for JAK1 were used for this study. The siRNA sequences are as follows: JAK1 siRNA1: sense 5'-GCUCUGGUAUGCUCCAAAUTT-3' and antisense 5'-AUUUGGAGCAUACCAGAGCTT-3'; JAK1 siRNA2: sense 5'-CCUGGCCAUCUCACACUAUTT-3' and antisense 5'-AUAGUGUGAGAUGGCCAGGTT-3'; JAK1 siRNA3: sense 5'-CCCAGAAGCAGUUCAAGAATT-3' and antisense 5'-UUCUUGAACUGCUUCUGGGTT-3'. The transfection of JAK1 siRNA or siRNA control was performed using Lipofectamine 2000 following the manufacturer's instructions. To evaluate transfection efficiency, cells were harvested $24 \mathrm{~h}$ post transfection for JAK1 real time PCR or harvested $36 \mathrm{~h}$ post transfection for JAK1 Western blotting assays.

Statistical analysis

Data were presented as mean \pm SEM of three independent experiments. Two-tailed Student's $t$ test was performed for all comparisons between two groups. One-way ANOVA was performed when three or more groups were compared.

\section{Results}

MiR-9 inhibits IL-1 $\beta$ expression and NLRP3 inflammasome activation in oxLDL-stimulated human THP-1 derived macrophages

Initially, we confirmed that oxLDL elicited IL-1 $\beta$ expression and release in human THP1 derived macrophages by Western blotting assays, real-time PCR and ELISA. The levels of both the active form of IL-1 $\beta$ (IL-1 $\beta$ p17) in cell culture medium and the precursor form of IL-1 $\beta$ (pro-IL-1 $\beta$ p31) in cell lysates were elevated (Fig. 1A). By contrast, pre-miR-9 pretreatment mitigated both the active and precursor form of IL-1 $\beta$ (versus miRNA negative control, pre-NC, p<0.05), while miR-9 inhibitor (anti-mir-9, an antisense oligonucleotide blocking mir-9 expression) pretreatment increased both the active and precursor form of IL-1 $\beta$ (versus miRNA inhibitor negative control, anti-NC, p<0.05) (Fig. $1 \mathrm{~A}$ ). ELISA also showed that pre-miR-9 decreased, while miR-9 inhibitor increased IL-1 $\beta$ release (Fig. 1 C). A consistent trend was observed in the mRNA level of IL-1 $\beta$ (Fig. 1D). All these methods verified that miR-9 inhibited IL-1 $\beta$ expression and secretion. 


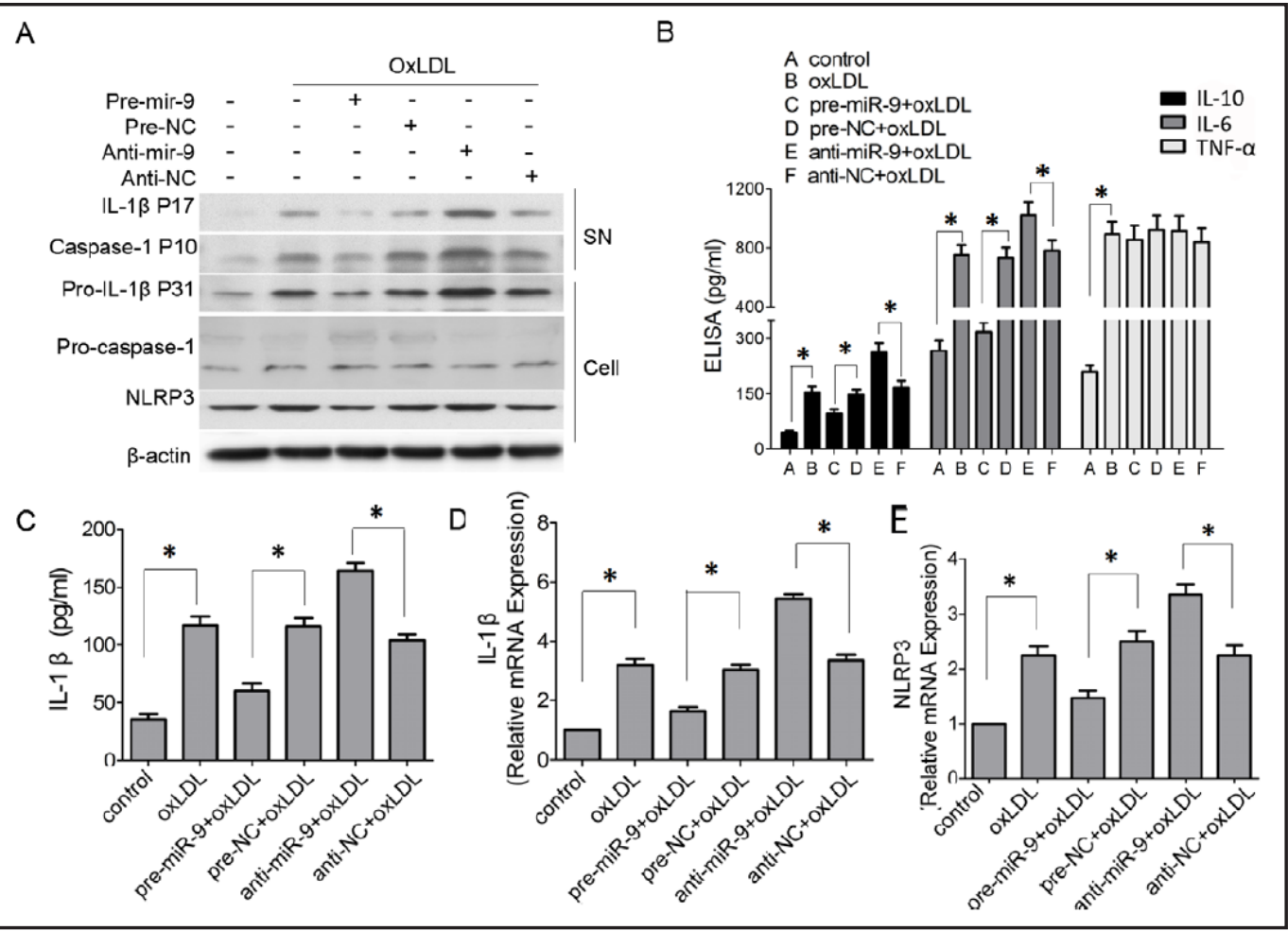

Fig. 1. MiR-9 inhibits IL-1 $\beta$ expression and NLRP3 inflammasome activation in oxLDL-stimulated human THP-1 derived macrophages. Human THP-1 derived macrophages were pretreated with miR-9 precursor or miR-9 inhibitor and then stimulated with oxLDL. The active form of IL-1 $\beta$ (IL-1 $\beta$ p17) and the active form of caspase-1 (caspase-1 p10) in cell culture medium, and the precursor form of IL-1 $\beta$, pro-caspase- 1 , and NLRP3 in cell lysates were determined by Western blotting assays (A). IL-1 $\beta$ secretion was measured by ELISA (C) and mRNA level of IL-1 $\beta$ was measured by real-time PCR (D). The secretion of inflammatory factors (IL-6, IL-10 and TNF- $\alpha$ ) was measured by ELISA (B). The mRNA level of NLRP3 was measured by real time PCR (E). Data are shown as mean \pm SEM of at least three independent experiments $(* P<0.05,2$-tailed Student's $t$ test).

The cleavage of IL- $1 \beta$ is mediated by caspase- 1 , a proenzyme ( $45 \mathrm{kDa}$ ) which is autoproteolytically cleaved into active $10 \mathrm{kDa}$ and $20 \mathrm{kDa}$ forms upon activation ofthe inflammasome [12]. We further detected the active form of caspase-1 by Western blotting assays. As demonstrated in Fig. 1A, oxLDL significantly enhanced the levels of active caspase-1 (caspase-1 p10). Pre-miR-9 mitigated oxLDL-induced activation of caspase-1 (versus preNC, p<0.05), whereas miR-9 inhibitor elevated the levels of active caspase-1. However, there was no significant difference in pro-caspase- 1 levels among all groups (Fig. $1 \mathrm{~A}$ ). This data suggests that miR-9 inhibits caspase- 1 activation in oxLDL-stimulated human THP- 1 derived macrophages.

The NLRP3 inflammasome signaling pathway is well-known to regulate caspase-1 activation and subsequent cleavage of IL-1 $\beta$. We further determined the protein and mRNA levels of NLRP3 in oxLDL-stimulated human THP-1 derived macrophages. As shown in Fig. $1 \mathrm{~A}$, pre-incubation of pre-miR-9 prior to the addition of oxLDL significantly decreased both the protein and mRNA levels of NLRP3 compared with the negative control group (pre-NC). On the other hand, pre-incubation of miR-9 inhibitor prior to the addition of oxLDL resulted in elevated protein and mRNA levels of NLRP3 (versus anti-NC, $\mathrm{p}<0.05$ ). These findings suggest that miR-9 inhibits NLRP3 inflammasome activation, which leads to less caspase-1 activation and reduced IL-1 $\beta$ secretion.

We also tested the impact of miR-9 on the secretion of other inflammatory factors by ELISA. As shown in Fig. 1 B, pre-miR-9 pretreatment significantly decreased IL-6 and IL-10 


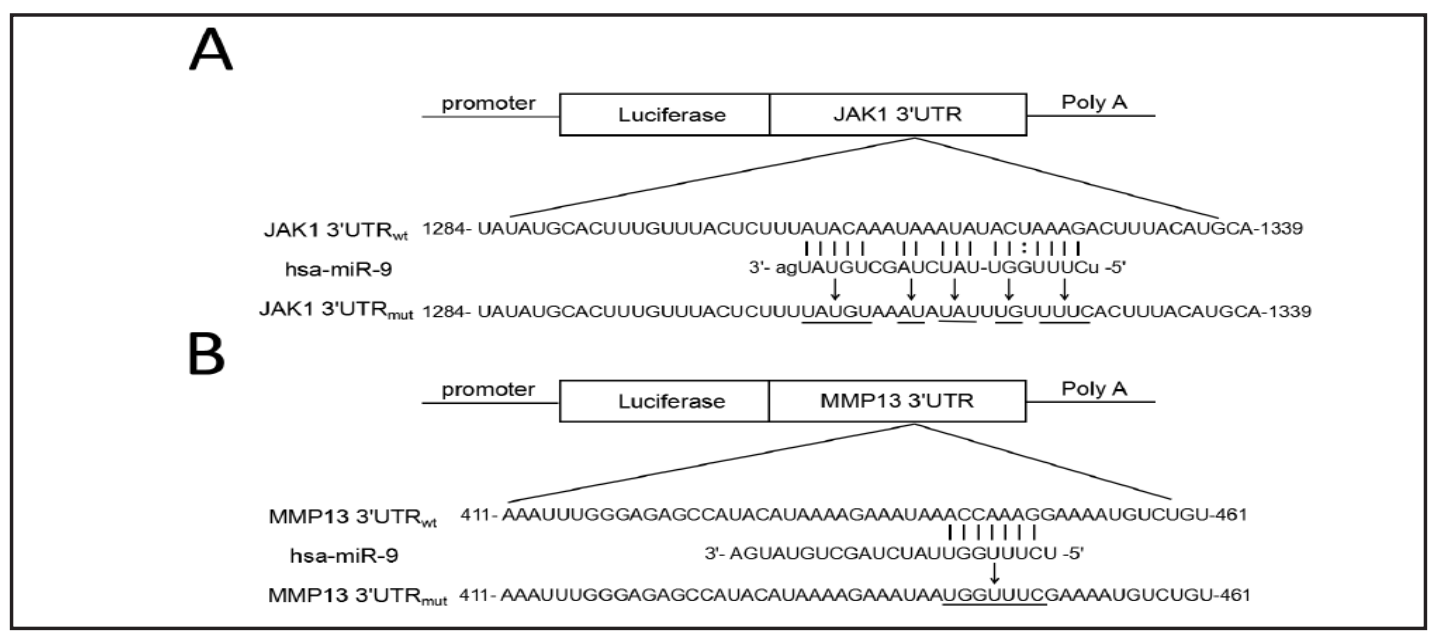

Fig. 2. Diagrams of JAK1 and MMP-13 3'UTR luciferase reporters. Diagram of luciferase reporter vector for JAK1 3'UTR. A 56 bp sequence containing mir-9 binding site (wt 3'UTR) or with mir-9 binding site mutated (mut 3'UTR) was inserted into a psiCHECKTM-2 firefly luciferase reporter (A). Diagram of luciferase reporter vector for MMP-13 3'UTR. A 51 bp sequence containing mir-9 binding site (wt 3'UTR) or with mir-9 binding site mutated (mut 3'UTR) was inserted into a psiCHECKTM-2 firefly luciferase reporter (B). The underlined nucleotides are mutated for JAK1 or MMP-13 3'UTR.

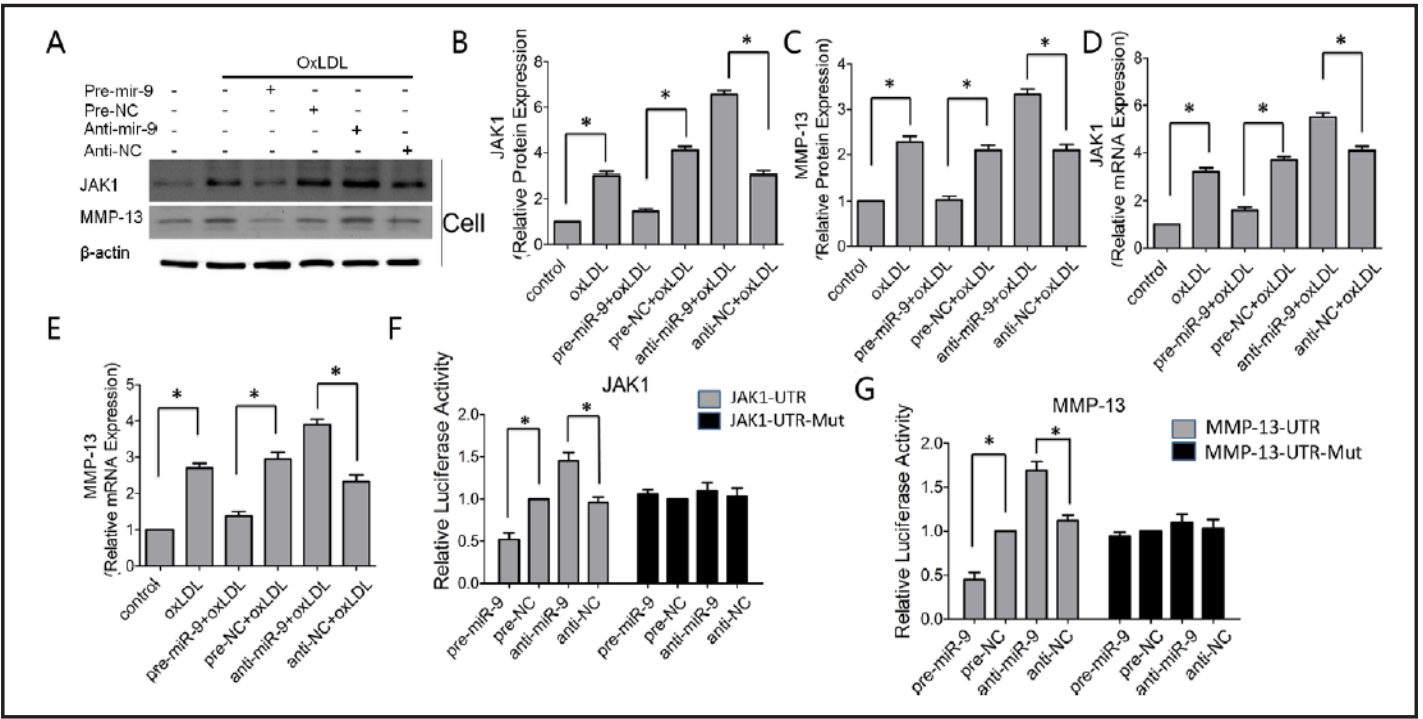

Fig. 3. JAK1 and MMP-13 are miR-9 targets. Human THP-1 derived macrophages were transfected with miR-9 precursor (pre-miR-9), miR-9 inhibitor (anti-miR-9) or their negative control (NC), the protein level of JAK1 and MMP-13 was determined by Western blotting assays (A-C), and the mRNA levels of JAK1 and MMP-13 were determined by real-time PCR (D-E). The firefly luciferase reporter vectors containing wt 3'UTR or mut 3'UTR for either JAK1 or MMP-13 were transfected into human THP-1 derived macrophages together with a constitutively active renilla luciferase vector. Upon treatment of pre-miR-9 or anti-miR-9, and luciferase reporter assay for JAK1 (F) or MMP-13 (G) was performed. Renilla luciferase activity was used a control for transfection efficiency. ( ${ }^{*} P<0.05,2$-tailed Student's $t$ test).

protein level in the culture supernatant, which was increased by oxLDL stimulation (versus pre-NC, $\mathrm{p}<0.05$ ). Compared to the anti-NC group, the anti-miR-9 group showed an increase in IL- 6 and IL-10 protein levels (versus anti-NC, $p<0.05$ ). The secretion of TNF- $\alpha$ was not affected by pre-mir-9 or anti-mir-9 treatment (Fig. 1 B).

\section{KARGER}




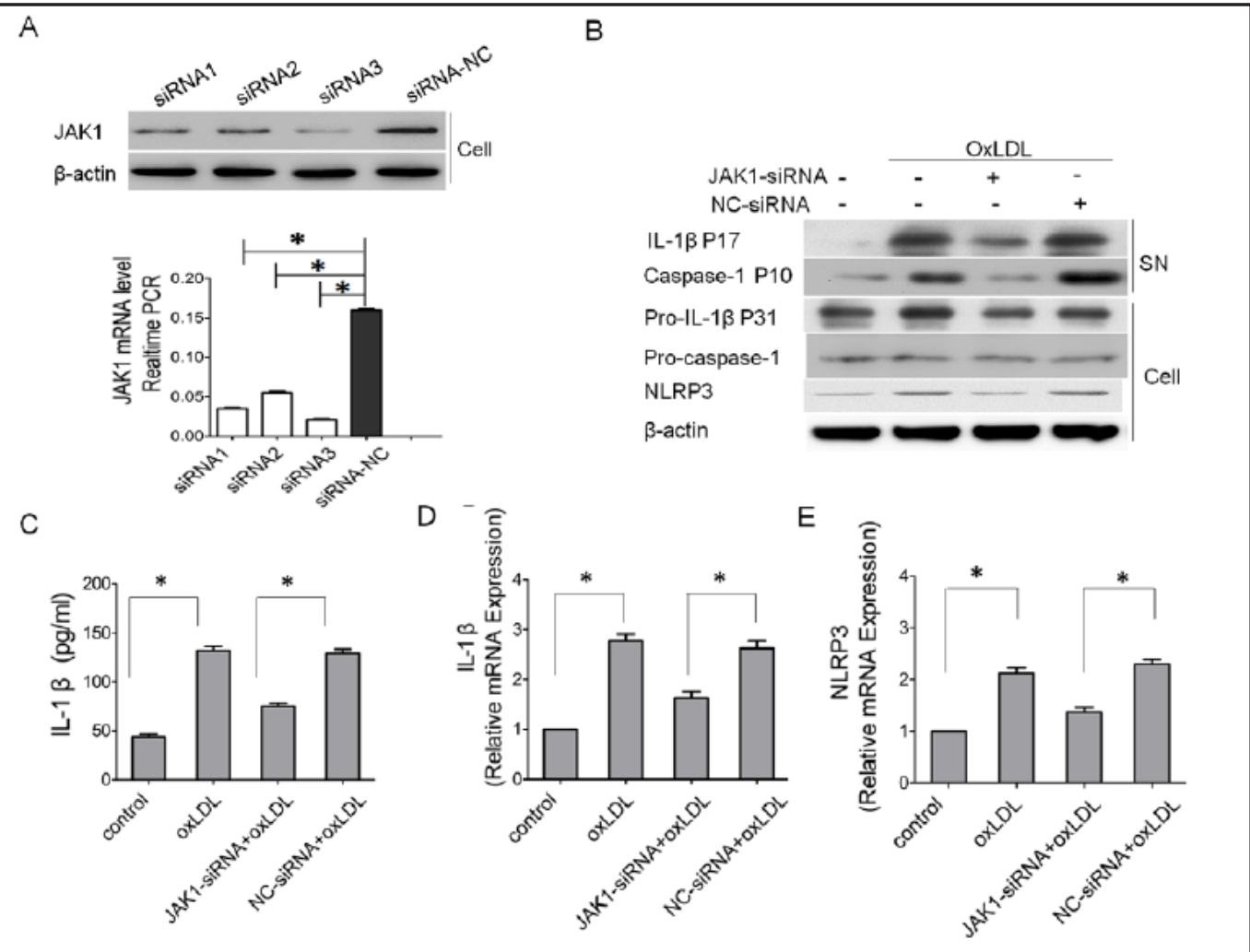

Fig. 4. JAK1 siRNA inhibits NLRP3 inflammasome activation in oxLDL-stimulated human THP-1 derived macrophages. Human THP-1 derived macrophages were transfected with 3 individual siRNAs specific for JAK1 siRNAs or a control siRNA. Real time PCR (24 h post transfection) and Western blotting assays (36 $\mathrm{h}$ post transfection) were performed to detect JAK1 mRNA and protein levels, respectively, to determine transfection efficiency (A). To test the effect of JAK1 in NLRP3 inflammasome activation, we transfected human THP-1 derived macrophages with JAK1 siRNA or control siRNA and then stimulated the macrophages

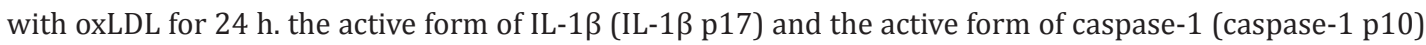
in cell culture medium, and the precursor form of IL-1 $\beta$ (pro-IL-1 $\beta$ p31), pro-caspase-1, and NLRP3 in cell lysates were determined by Western blotting assays (B). Secreted IL-1 $\beta$ level was measured by ELISA (C). The mRNA level of IL-1 $\beta$ or NLRP3 was measured by real time PCR (D, E). Data are shown as mean \pm SEM. The data shown are representative of three independent experiments ( ${ }^{*} P<0.05,2$-tailed Student's $t$ test).

\section{MiR-9 downregulates JAK1 expression in oxLDL-stimulated human THP-1 derived macrophages}

To identify potential target genes of miR-9, we searched multiple databases (Targetscan, PicTar, and miRanda) and found two candidate genes, JAK1 and MMP-13. To validate this finding, we examined the correlation between the expression level of miR-9 and JAK1 or MMP-13 in human THP-1 derived macrophages. MiR-9 inhibitor significantly induced JAK1 protein (Fig. 3 A, B) and mRNA levels (Fig. 3 D) in oxLDL-stimulated human THP-1 derived macrophages, while pre-miR-9 significantly inhibited JAK1 mRNA and protein levels in the same model. Similarly, miR-9 inhibitor significantly increased MMP-13 protein and mRNA levels in oxLDL-stimulated human THP-1 derived macrophages, while pre-miR-9 significantly inhibited MMP-13 mRNA and protein levels in the same cells (Fig. 3 A, C, E).

Next, we performed a dual luciferase reporter gene assay to further examine whether JAK1 was a direct target of miR-9. A 56-bp fragment of the wild type miR-9 binding sequence for JAK1 3'-UTR (wt3'UTR) or a mutated sequence (mut 3'UTR) was cloned into a firefly luciferasereporter vector, downstream of the reporter gene (Fig. 2A). Similarly a MMP-13 wt3'UTR luciferase reporter vector and a mutated version (MMP-13 mut 3'UTR) luciferase reporter vector were made (Fig. 2B). Either miR-9 precursor or miR-9 inhibitor was used to 
modulate miR-9 level. As expected, pre-miR-9 inhibited, whereas miR-9 inhibitor promoted firefly luciferase activity in human THP-1 derived macrophages transfected with a JAK1 wt 3'UTR reporter vector (Fig. 3F). However, this effect was abolished in cells transfected with JAK1 mut 3'UTR vector, a reporter vector containing mutated JAK1 3'UTR for miR-9 binding site (Fig. 3F), suggesting that JAK1 is a direct target of miR-9 in human THP-1 derived macrophages. Using the same approach, we showed that MMP-13 was also a direct target of miR-9 in human THP-1 derived macrophages (Fig. 3G).

\section{JAK1 siRNA inhibits IL-1 $\beta$ release and NLRP3 activation in oxLDL-stimulated human THP-} 1 derived macrophages

To investigate the role of JAK1 in NLRP3 signaling, we designed siRNAs to knock down JAK1 expression in human THP-1 derived macrophages. The knockdown efficiency of JAK1 was tested by real time PCR and Western blotting assays. As shown in Fig. 4A, $24 \mathrm{~h}$ after transfection, the JAK1 mRNA level in human THP-1 derived macrophages treated with JAK1 specific siRNA dropped to 14\% compared to control. Forty-eight hours after transfection, cells transfected with JAK1 siRNA remained low for JAK1 mRNA (19\% versus control). To detect the effect of JAK1 on IL-1 $\beta$ expression, we transfected human THP-1 derived macrophages with JAK siRNA or control siRNA, and stimulated the macrophages with oxLDL for $24 \mathrm{~h}$. As shown in Fig. 4B by Western blotting assays, the active form of IL-1 $\beta$ induced by oxLDL was attenuated in the presence of JAK1 siRNA, but not by control siRNA. In addition, the precursor level of IL-1 $\beta$ was also significantly decreased in the JAK1 siRNA group, but not in the control siRNA group (Fig. 4B). A similar pattern was observed in IL-1 $\beta$ mRNA levels in the presence of JAK1 siRNA or control siRNA (Fig. 4D). Consistently, JAK1 siRNA significantly inhibited the release of IL- $1 \beta$ compared with control siRNA (Fig. 4C).

We further examined the mRNA and protein level of NLRP3 and caspase-1 in oxLDLstimulated human THP-1 derived macrophages. As shown in Fig. 4E, NLRP3 mRNA expression was significantly down-regulated in the JAK1 siRNA group compared with that in the control siRNA group. Consistently, NLRP3 protein level was also down-regulated in the JAK1 siRNA group compared with the control siRNA group (Fig. 4B). In addition, JAK1 siRNA treatment prior to the addition of oxLDL resulted in reduced levels of active caspase-1 in the culture medium compared with that in the control siRNA group (Fig.4 B). However, there was no significant difference in pro-caspase-1 expression levels among all groups (Fig. 4B). Overall, these findings suggest that JAK1 siRNA inhibits the activation of the NLRP3 inflammasome.

To explore whether STAT1 is a downstream effector of JAK1, we transfected human THP-1 derived macrophages with JAK1 siRNA or control siRNA, followed by stimulation with oxLDL for $4 \mathrm{~h}$ [33]. Phosphorylated STAT1 levels in the nuclei and total STAT1 levels in the cell were detected by Western blotting assays. As shown in Fig. 5A, B, oxLDL significantly enhanced the levels of phosphorylated STAT1 and total STAT1 compared with the negative control group. The addition of JAK1 siRNA to oxLDL treated cells significantly decreased the phosphorylated STAT1 level compared with the same cells receiving negative control siRNA NC-siRNA. The total STAT1 level was slightly decreased by JAK1 siRNA (Fig. 5A, B).

\section{JAK1 knockdown abolishes the induction of IL-1 $\beta$ and NLRP3 caused by anti-miR-9}

OxLDL is the most important inflammatory stimulus in the pathogenesis of atherosclerosis. OxLdL could induce a series of inflammatory signaling pathways which lead to NLRP3 inflammasome activation in human THP-1 derived macrophages. To further explore the role of JAK1 in oxLDL-stimulated NLRP3 activation, we knocked down JAK1 with siRNA in human THP-1 derived macrophages treated with anti-miR-9, an antisense oligonucleotides that blocked miR-9 expression. We first observed that anti-miR-9 dramatically increased protein expression of IL-1 $\beta$ p17. However, if we also knocked down JAK1 by siRNA along with anti-miR-9 treatment, the protein expression of IL-1ßp17 was significantly lower compared to cells receiving only anti-miR-9 but not JAK1 siRNA (Fig. 6A, B). There was no significant difference in IL-1 $\beta$ p17 protein expression level between cells 


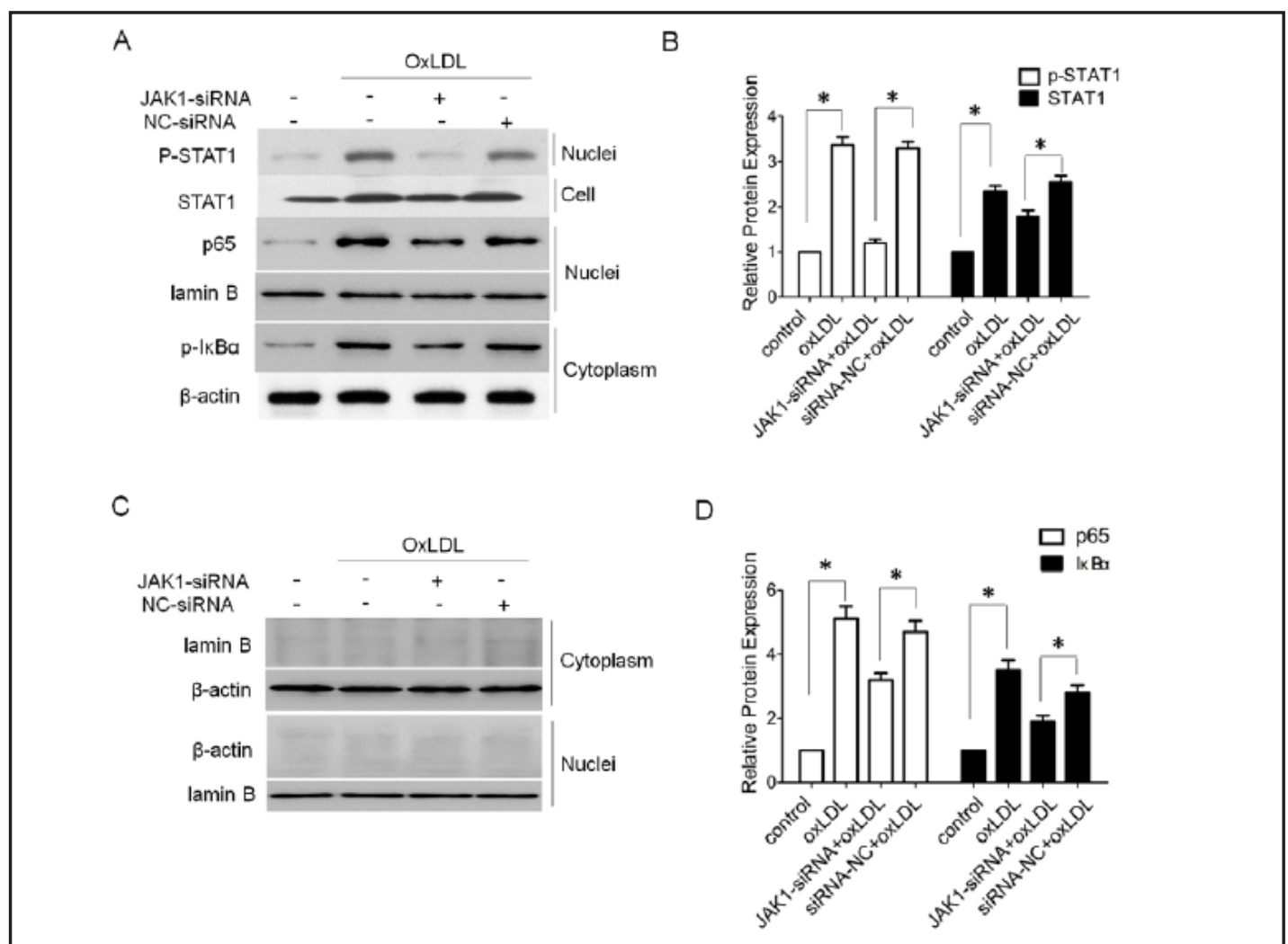

Fig. 5. STAT1 and NF- $\kappa B$ are downstream of JAK1. Human THP-1 derived macrophages were transfected with JAK1 siRNA or NC-siRNA and then stimulated with oxLDL. Nuclear protein samples, cytoplasmic protein samples and total protein samples were extracted separately. Phosphorylated STAT1 (p-STAT1) and total STAT1 (STAT1) level in total protein samples were determined by Western blotting assays (A, B). p65 level in nuclear protein samples and phosphorylated $\mathrm{I} \kappa \mathrm{B} \alpha$ level in cytoplasmic protein samples were determined by Western blotting assays (A, D) $\left({ }^{*} P<0.05,2\right.$-tailed Student's $t$ test). The fractionation of nuclear and cytoplasmic proteins was shown by Western blotting assays with lamin B as nuclear protein marker and $\beta$-actin as cytoplasmic protein marker (C).

receiving anti-miR-9 only and cells receiving both anti-miR-9 and control siRNA. There was also no significant difference in IL-1 $\beta$ p17 protein levels between cells stimulated by oxLDL with or without anti-NC, which did not block miR-9 expression.

The protein expression of NLRP3 had a similar pattern to that of IL-1 $\beta$ p17. Anti-miR-9 enhanced NLRP3 expression, which, however, was blocked by JAK1 siRNA (Fig. 6A, C). Again, this inhibition of anti-miR-9 induced NLRP3 expression was not seen with control siRNA. Negative control miRNA anti-NC also did not change NLRP3 expression level in oxLDLstimulated human THP-1 derived macrophages.

\section{JAK1 siRNA inhibits NF- $K B$ activation in oxLDL-stimulated human THP- derived macrophages}

oxLDL was reported to activate NF- $\kappa B$ in human THP-1 cells. IL-1 $\beta$ is one of NF- $\kappa B$ target genes, which would be upregulated when NF- $\kappa B$ signaling pathway is activated. We used JAK1 siRNA to test whether JAK1 was involved in oxLDL stimulated NF- $\mathrm{BB}$ activation. As shown in Fig. $5 \mathrm{~A}$ and $\mathrm{D} 6 \mathrm{~h}$ after oxLdL addition the level of phospho-IкB $\alpha$ increased dramatically in cytoplasm while the expression of p65 increased dramatically in nuclei, indicating activation of NF- $\kappa B$ signaling pathway by oxLDL inhuman THP-1 derived macrophages, which was consistent with previous literature. This activation of NF- $\kappa B$ signaling pathway by oxLDL was inhibited by JAK1 siRNA shown by dramatically decreased phospho-IкB $\alpha$ in cytoplasm and p65 in nuclei (Fig. 5 A,D. The effective fractionation of nuclear and cytoplasmic proteins was 


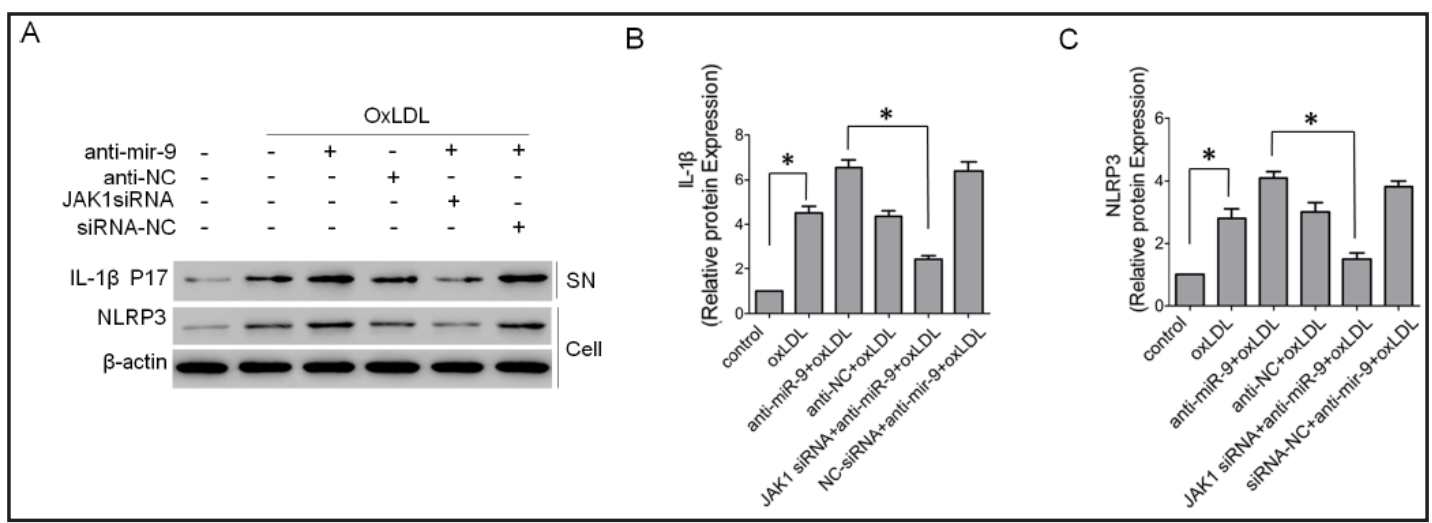

Fig. 6. JAK1 plays a key role in decreasing NLRP3 inflammasome activation by mir-9 in human THP-1 derived macrophages. HumanTHP-1 derived macrophages were pretreated with anti-mir-9 with or without JAK1 siRNA and then stimulated with oxLDL. IL-1 $\beta$ protein level (A, B) and NLRP3 protein level were measured by Western blotting assays $(A, C)$. Data are shown as mean \pm SEM. The data shown are representative of three independent experiments $\left({ }^{*} P<0.05,2\right.$-tailed Student's $t$ test $)$.

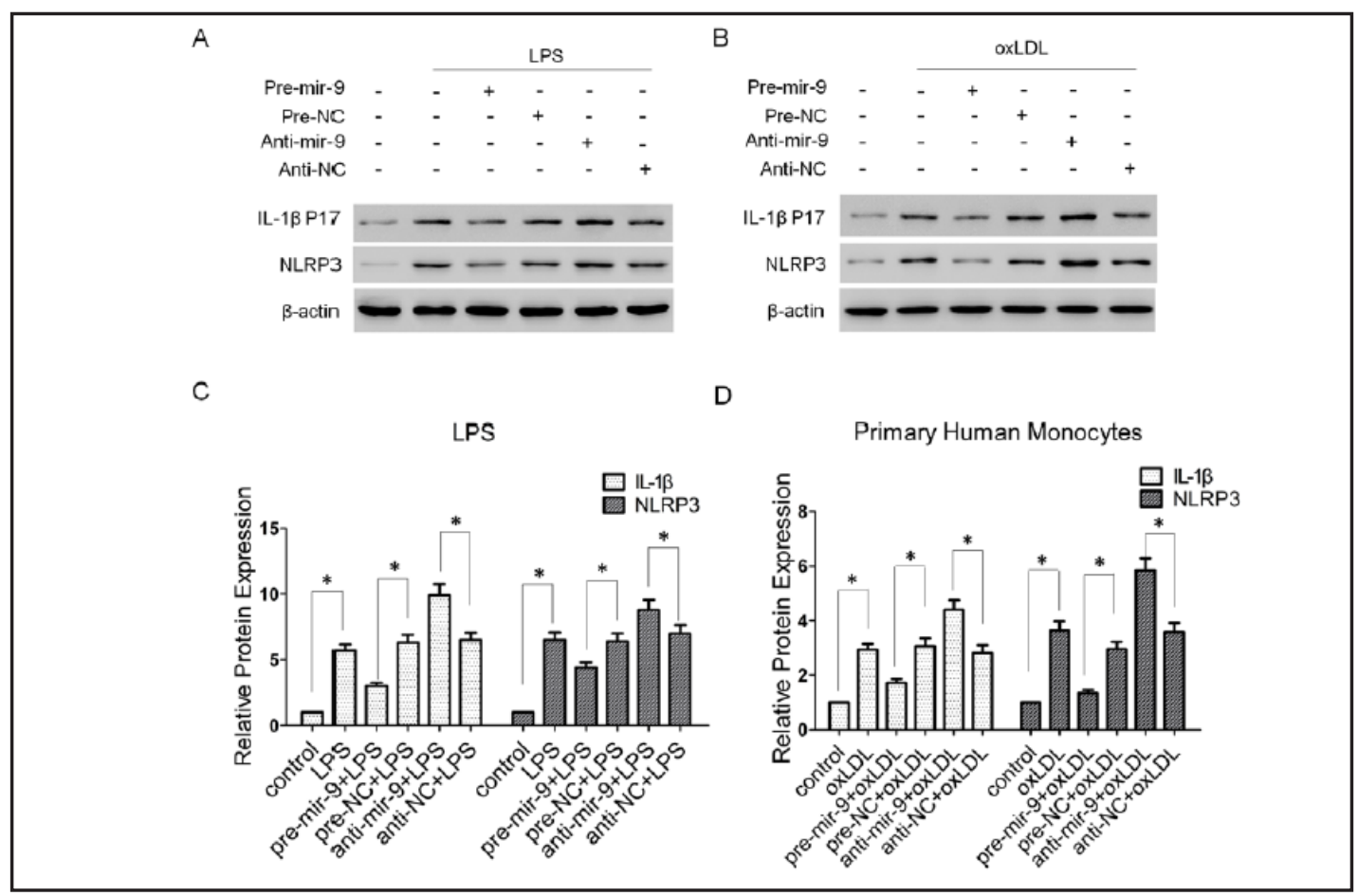

Fig. 7. Mir-9 inhibits NLRP3 inflammasome activation induced by LPS in human THP-1 derived macrophages. Mir-9 inhibits NLRP3 inflammasome activation induced by oxLDL in human primary peripheral blood monocytes. Human THP-1 derived macrophages were pretreated with miR-9 precursor or miR-9 inhibitor and then stimulated with $100 \mathrm{ng} / \mathrm{mL}$ LPS for $24 \mathrm{~h}$. IL-1 $\beta$ protein level and NLRP3 protein levels were measured by Western blotting assays (A, C). Human primary peripheral blood monocytes were pretreated with miR-9 precursor or miR-9 inhibitor and then stimulated with oxLDL. IL-1 $\beta$ protein level and NLRP3 protein levels were measured by Western blotting assays (B, D). Data are shown as mean \pm SEM. The data shown are representative of three independent experiments $\left({ }^{*} P<0.05,2\right.$-tailed Student's $t$ test).

demonstrated by exclusive lamin B presence in nuclear proteins and $\beta$-actin in cytoplasmic proteins (Fig. 5C). The control siRNA for JAK1 had no effect, suggesting a critical role of JAK1 in oxLDL-stimulated human THP-1 derived macrophages.

\section{KARGER}




\section{Cellular Physiology Cell Physiol Biochem 2017;41:1555-1571

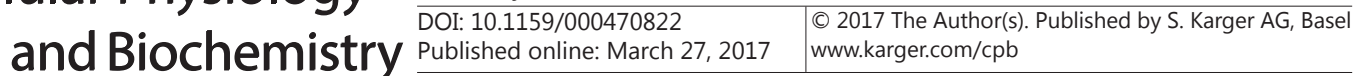

Fig. 8. Mir-9 inhibits NLRP3 inflammasome activation induced by Alum in human THP-1 derived macrophages. Human THP-1 derived macrophages were pretreated with miR-9 precursor or miR-9 inhibitor and then stimulated with $130 \mu \mathrm{g} / \mathrm{mL}$ Alum for $4 \mathrm{~h}$. IL-1 $\beta$ protein levels in the supernatant and NLRP3 protein levels in total cell lysates were measured by Western blotting assays. Data are shown as mean \pm SEM. The data shown are representative of three independent experiments $\left({ }^{*} P<0.05\right.$, 2-tailed Student's $t$ test).

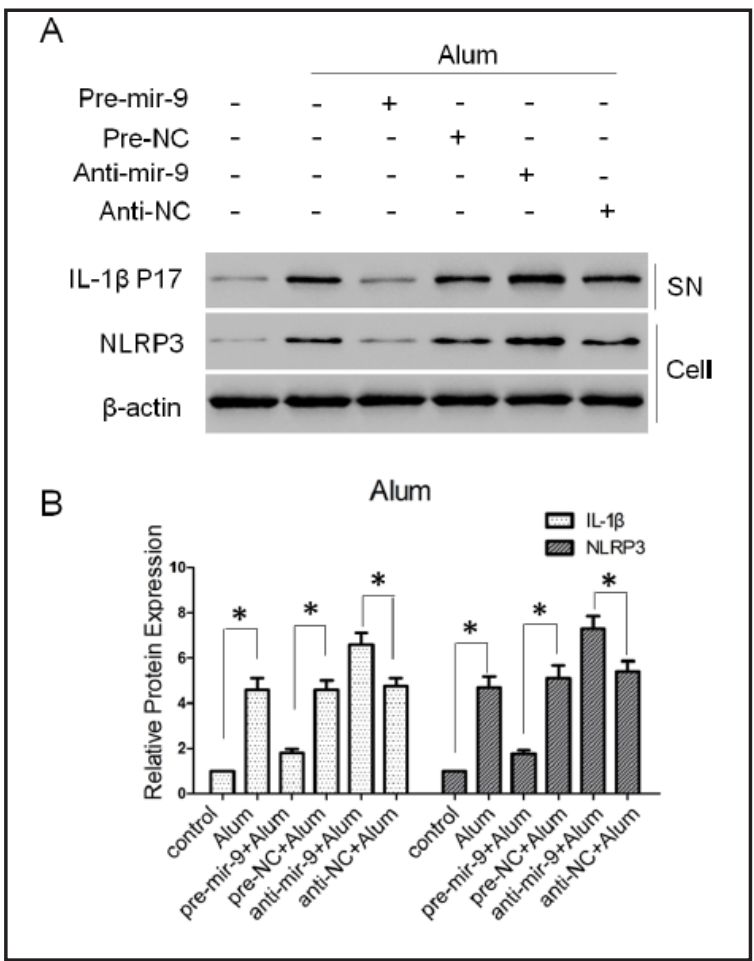

MiR-9 inhibits IL-1 $\beta$ and NLRP3 expression in LPS-stimulated human THP-1 derived macrophages

LPS is a classic inflammatory stimulus and has been reported to activate the NLRP3 inflammasome[26, 27, 34]. To explore the effect of miR-9 in LPS-stimulated human THP1 derived macrophages, we examined by Western blotting assays the expression of IL-1 $\beta$ and NLRP3, two key proteins in NLRP3 inflammasome activation. Consistent with previous reports, the addition of LPS dramatically upregulated the expression of IL-1 $\beta$, which was further elevated by anti-mir-9. In contrast, pre-mir-9 dramatically suppressed LPS-induced IL-1 $\beta$ expression (Fig. 7A, C). All results were statistically significant.

Consistent with literature, LPS greatly upregulated NLRP3 expression in human THP-1 derived macrophages. This induction could be further enhanced by anti-mir-9, but blocked by pre-mir-9. All results were statistically significant (Fig. 7A, C).

MiR-9 inhibits IL-1 $\beta$ and NLRP3 expression in Alum-stimulated human THP-1 derived macrophages

Alum has been reported as one of the stimuli of the NLRP3 inflammasome [28]. We also tested the effects of miR-9 on expression of IL-1 $\beta$ and NLRP3 in Alum-stimulated human THP-1 derived macrophages. Consistent with previous findings, the addition of Alum dramatically upregulated the expression of IL-1 $\beta$, which was further elevated by anti-mir-9. In contrast, pre-mir-9 dramatically suppressed Alum induced IL-1 $\beta$ expression (Fig. 8). All results were statistically significant.

Consistent with literature, Alum greatly upregulated NLRP3 expression in human THP1 derived macrophages. This induction was further enhanced by anti-mir-9, but blocked by pre-mir-9. All results were statistically significant (Fig. 8).

MiR-9 inhibits IL-1 $\beta$ and NLRP3 expression in oxLDL-stimulated human primary peripheral blood monocytes

We also explored the effect of mir-9 in oxLDL stimulated human primary peripheral blood monocytes and found similar results as in human THP-1 derived macrophages. oxLDL treatment dramatically induced IL- $1 \beta$ expression in human primary peripheral blood 
Wang et al.: MicroRNA-9 Inhibits NLRP3 Inflammasome Activation

monocytes. When we added anti-mir-9 along with oxLDL, the expression of IL-1 $\beta$ was further upregulated. On the other side, pre-mir-9 which increased mir-9 expression inhibited the upregulation of IL-1 $\beta$ expression induced by oxLDL. All results were statistically significant (Fig. 7B, D)

The addition of oxLDL also increased NLRP3 expression in human primary peripheral blood monocytes. Again, this increase was further boosted by anti-mir-9, but reduced by pre-mir-9. All results were statistically significant (Fig. 7B, D).

\section{Discussion}

MiRNAs have been reported to be involved in inflammatory process of atherosclerosis [19-22]. However, little is known about miR-9, a highly conserved miRNA, which was originally thought to be predominantly expressed in the central nerve system in embryo development [35]. Later, miR-9 was also found to be expressed in other cell types including macrophages [36], neutrophils [36], and tumor cells [37]. Our previous study revealed that miR-9 mRNA expression is obviously increased in oxLDL-stimulated human primary peripheral blood monocytes [24]. One important question is whether the increased miR-9 expression works as an inflammation regulator or just a result of inflammation reaction. In the present study, we further explored the effect of miR-9 on oxLDL-stimulated human THP-1 derived macrophages and human primary peripheral blood monocytes. Our data demonstrated for the first time that miR-9 inhibited activation of the NLPR3 inflammasome in these two cell models and JAK1 was one of the miR-9 target genes. Through targeting the JAK1/STAT1 signaling pathway, miR- 9 decreased IL- $1 \beta$ expression, caspase- 1 activation, and NLRP3 expression. MiR-9 inhibited the secretion of inflammatory factors and NF- $\kappa B$ activation in oxLDL-stimulated human THP-1 derived macrophages. It also inhibited IL-1 $\beta$ and NLPR3 expression in LPS or Alum-stimulated human THP-1 derived macrophages. We also found another miR-9 target gene $M M P-13$, which plays a vital role in the regulation and organization of collagen in atherosclerotic plaques [33].

MiR-9 has been reported to play important roles in inflammatory response [36], immune regulation [36], lipid uptake [38], neuron differentiation [39], and many kinds of tumors [40]. Our results indicate potential anti-inflammatory effects and inhibition of NLRP3 inflammasome by mir-9. There is little study of interaction of mir-9 and inflammasome. Mir-9 was reported to suppress activation of the NLRP3 inflammasome in cardiomyocytes. Through regulating its target gene ELAVL1, mir-9 inhibited hyperglycemiainduced pyroptosis (cardiac cell death) in human ventricular cardiomyocytes. ELAVL1 knockdown abrogates TNF- $\alpha$ induced canonical pyroptosis via NLRP3, caspase- 1 and IL-1 $\beta$ suppression[40]. Over-expression of miR-9 in isolated human chondrocytes reduced IL-1 $\beta$ induced TNF- $\alpha$ production and inhibited MMP-13 in human chondrocytes[41]. We found that mir-9 inhibited the expression of proinflammatory cytokines IL- 6 and IL-10 in oxLDL stimulated human THP-1 derived macrophages. The secretion of TNF- $\alpha$ was not affected by increased or decreased mir-9 expression. Both our study and early literature indicate possible critical roles of mir-9 in inflammatory reaction in atherosclerosis. Mir-9 therefore can be an important potential target for intervening atherosclerosis-related inflammation, which is worth further investigation.

The activation of the NLRP3 inflammasome and the release of the mature form of IL-1 $\beta$ require two separate signals. "Signal one" activates a pattern recognition receptor, such as Toll-Like Receptor 4 (TLR4), which induces synthesis of pro-IL-1 $\beta$. "Signal two" activates caspase- 1 , a protease that cleaves pro-IL-1 $\beta$ into a biologically active, secreted IL-1 [42]. OxLDL is the major proinflammatory stimulus of atherosclerosis and has been proposed to participate in both signal 1 and signal 2 for complete activation of the NLRP3 inflammasome, which is in line with our results [43]. We found that mir-9 could inhibit activation of NLRP3 inflammasome induced by oxLDL. Next, we used LPS and Alum as stimuli and further confirmed effects of mir-9 on the NLRP3 inflammasome. LPS is a classic and robust 
inflammation stimulus and has been reported to activate the NLRP3 inflammasome. Alum is an adjuvant commonly used in vaccine production and its role to stimulate NLRP3 dependent sterile inflammation has been recognized $[28,29]$. Inhibiting the formation of the NLRP3 inflammasome has been reported to reduce myocardial injury after ischemia-reperfusion [16]. NLRP3 inflammasome inhibitor arglabin markedly reduced atherosclerosis-related inflammation and atherosclerotic lesions [44]. The size of atherosclerotic plaque was significantly reduced in ApoE $E^{-C a s p-1 \%}$ double knockout mice compared with $A p o E^{-/}$single knockout mice [45]. Consistently, our finding provides new evidence regarding the crucial role of NLRP3 inflammasome activation in the pathogenesis of atherosclerosis.

MicroRNAs have been reported to regulate cellular functions through signaling pathways[46, 47]. The JAK/STAT signal pathway plays key roles in a variety of important cellular responses, such as inflammation, cell growth, metabolism, and gene transcription [45]. Our study found that JAK1/STAT1 was implicated in inflammatory reaction in oxLDLstimulated human THP-1 derived macrophages. In our study, anti-mir-9 treatmentsignificantly increased JAK1 mRNA and protein expression, while pre-mir-9 treatment significantly decreased JAK1 mRNA and protein expression. Luciferase reporter assay further validated that JAK1 is a mir-9 target gene. Functional study discovered that JAK1 siRNA significantly decreased mRNA level and active protein expression of IL-1 $\beta$ and caspase- 1 , and decreased NLRP3 mRNA and protein expression, similar to pre-mir-9 mediated inhibition of NLRP3 inflammasome activation. Therefore we conclude that mir-9 could suppress activation of downstream NLRP3 inflammasome through its target gene JAK1. Moreover, we knocked down JAK1 by siRNA and at the same time inhibited mir-9 expression to further explore the effects of JAK1 in mir-9 induced suppression of the NLRP3 inflammasome. Compared to anti-mir-9 only, JAK1 siRNA plus anti-mir-9 significantly lowered the expression of IL$1 \beta$ and NLRP3. The fact that mir-9 inhibition does not affect the function of JAK1 siRNA on downstream NLRP3 activation indicates that JAK1 is the crucial mediator of the effect of miR-9 on the expression of inflammasome components. It was reported that in mouse neural stem/progenitor cells (NPCs), JAK1 is one target gene of mir-9 identified by genetic approaches, which is consistent with our results [48]. They found that when mouse NPCs were transfected with miR-9, the protein expression of JAK1-STAT1/3 signaling components was reduced [48]. Zhang et al. reported that the JAK/STAT signaling pathway is involved in vascular smooth muscle cell (VSMC) proliferation and migration in early atherosclerosis [49]. Importantly, ruxolitinib (JAK1/JAK2 inhibitor) and tofacitinib (JAK3 inhibitor) have been approved to treat different autoimmune diseases, including psoriasis and rheumatoid arthritis [50]. However, Zhang et al. reported that miR-9 secreted by tumor cells could promote endothelial cell migration and angiogenesis by activating the JAK/STAT pathway [49]. The apparent discrepancies regarding the relation between miR-9 and the JAK/STAT pathway in these two studies may be due to different cell types and inflammatory status. As an important target of inflammation intervention, the roles of JAK1 in atherosclerosisrelated inflammatory reaction need more study in future research.

We found that STAT1 phosphorylation was inhibited by JAK1 siRNA, indicating that STAT1 was a downstream effector of JAK1 activation in oxLDL-stimulated human THP-1 derived macrophages. OxLDL has been proved to stimulate the binding activity of STAT1 in endothelial cells, fibroblasts and T lymphocytes [51,52]. Activation of STAT1 is downstream of the LPS-induced TLR4/NF- $\kappa$ B signaling cascade in murine RAW 264.7 macrophages, which leads to expression of proinflammatory factors such as IL- 6 and TNF- $\alpha$ [53]. Pharmacological inhibition of the JAK/STAT1 pathway or genetic deletion of STAT1 abrogated LPS- or type 1 IFN-induced HMGB1 cytoplasmic accumulation for subsequent release, which is a proinflammatory mediator during infection or sterile tissue injury [54]. Researchers also found that LPS could promote IL- $1 \beta$ and caspase- 1 protein expression in STAT1 $\%$ BMDM from C57BL/ 6 mice, indicating mediation of STAT1 in LPS stimulated NLRP3 inflammasome activation [55]. Different roles of JAK and STAT family members in inflammation reaction might be due to varied cell sources and stimuli.

\section{KARGER}


Continuous oxLDL stimulation can lead to cascade amplification of inflammatory reaction and persistent secretion of proinflammatory factors. NF- $\mathrm{KB}$ mediated signaling is the major pathway that modulates the pathogenesis of atherosclerotic plaques [39]. These findings support that miR-9 is highly associated with NF- $\kappa B$ related inflammation. Our work demonstrated that knockdown of JAK1 resulted in downregulation of NF- $\mathrm{BB}$ p65 in human THP-1 derived macrophage nuclei and reduction of NF- $\kappa \mathrm{B}$ p-IкB $\alpha$ in cytoplasm, suggesting that NF- $\kappa B$ could be a pathway downstream of JAK1. NF- $\kappa B 1$ was previously shown to be one of mir-9's target genes. MiR-9 inhibits melanoma cell proliferation and migration through down-regulation of the NF- $\kappa B 1-S n a i l 1$ pathway [40]. So it is possible for mir-9 to inhibit its downstream NF- $\kappa B$ signal transduction pathway through regulating JAK1. When oxLDL is added to human THP-1 derived macrophages, oxLDL could activate the JAK1/STAT1 and NF- $\kappa \mathrm{B}$ signaling pathways, promote NLRP3 inflammasome activation, and release of proinflammatory cytokines. On the other hand, oxLDL could cause upregulation of mir-9, which in turn suppresses expression of its target gene JAK1. Meanwhile the NF- $\kappa \mathrm{B}$ signaling pathway is blocked and eventually NLRP3 inflammasome activation and expression of NF$\kappa B$ target genes such as IL-1 $\beta$, IL- 6 and IL-10 inflammatory factors are prohibited. The whole cellular responses make a negative feedback system. As a result, mir- 9 can modulate inflammatory reaction in more than one ways, including direct and indirect effects on the NF- $\kappa B$ signaling pathway.

In addition, Xu et al. reported an interesting finding that miR- 9 could target acetyl-CoA acetyltransferase 1 (ACAT1) to decrease the formation of foam cells from THP-1-derived macrophages [38]. Alternatively, miR-9 mediated decrease of foam cells formation may be explained as a direct result of inhibited NLRP3 activation and alleviated IL-1 $\beta$ release, or a changed NF- $\kappa B$ signaling pathway. Nevertheless, these points need further investigation.

\section{Conclusion}

Taken together, our data provides evidence that miR-9 inhibits NLRP3 inflammasome activation in oxLDL-stimulated human THP-1 derived macrophages and human primary peripheral blood monocytes. Our data also proves JAK1 as one target gene of miR-9, and the anti-inflammatory effect of miR-9 is at least partially through its interaction with the JAK1/STAT1 signaling pathway. Because the NLRP3 inflammasome plays a crucial role in atherosclerosis and inflammation, our findings shed novel insights into the regulatory effect of atherosclerosis-related inflammation and roles of miR-9, which maybe a potential therapeutic target for atherosclerosis.

\section{Abbreviations}

miRNA (microRNAs); NLRP3 (nucleotide-binding domain and leucine rich repeat containing family, pyrin domain containing 3); ASC (apoptosis-associated speck like protein containing a caspase-recruitment domain); IL-1 $\beta$ (interleukin-1 beta); IL-6 (interleukin-6); IL-10 (interleukin-10); TNF- $\alpha$ (tumor necrosis factor alpha); NF- $\kappa B$ (nuclear factorkappa B); oxLDL (oxidized low-density lipoprotein); JAK1 (Janus kinase 1); STAT1 (signal transducer and activator of transcription 1); pre-NC (pre-negative control); ACAT1 (acetylCoA acetyltransferase 1); ANOVA (One-way analysis of variance); PCR (polymerase chain reaction); cDNA (Complementary DNA); MMP-13 (matrix metalloproteinase 13).

\section{Funding}

This work was funded by the National Natural Science Foundation of China (81500392 and 81500382), and the Fund of Shanghai Municipal Commission of Health and Family Planning (ZY3-CCCX-3-3006 and ZY3-CCCX-3-3002).

\section{KARGER}




\section{Cellular Physiology Cell Physiol Biochem 2017;41:1555-1571 \begin{tabular}{ll|l} 
DOI: 10.1159/000470822 & ( 2017 The Author(s). Published by S. Karger AG, Basel \\
www.karger.com/cpb
\end{tabular} \\ Wang et al.: MicroRNA-9 Inhibits NLRP3 Inflammasome Activation}

\section{Disclosure Statement}

The authors declare that they have no competing interests.

\section{References}

Libby P, Ridker PM, Maseri A: Inflammation and atherosclerosis. Circulation 2002;105:1135-1143.

Ross R: The pathogenesis of atherosclerosis: a perspective for the 1990s. Nature 1993;362:801-809.

Chen JW, Chen YH, Lin SJ: Long-term exposure to oxidized low-density lipoprotein enhances tumor necrosis factor-alpha-stimulated endothelial adhesiveness of monocytes by activating superoxide generation and redox-sensitive pathways. Free Radic Biol Med 2006;40:817-826. Osterud B, Bjorklid E: Role of monocytes in atherogenesis. Physiol Rev 2003;83:1069-1112. Shashkin P, Dragulev B, Ley K: Macrophage differentiation to foam cells. Curr Pharm Des 2005;11:30613072.

6 Tabas I: Consequences and therapeutic implications of macrophage apoptosis in atherosclerosis: the importance of lesion stage and phagocytic efficiency. Arterioscler Thromb Vasc Biol 2005;25:2255-2264. Duewell P, Kono H, Rayner KJ, Sirois CM, Vladimer G, Bauernfeind FG, Abela GS, Franchi L, Nunez G, Schnurr M, Espevik T, Lien E, Fitzgerald KA, Rock KL, Moore KJ, Wright SD, Hornung V, Latz E: NLRP3 inflammasomes are required for atherogenesis and activated by cholesterol crystals. Nature 2010;464:1357-1361.

-8 Rajamaki K, Lappalainen J, Oorni K, Valimaki E, Matikainen S, Kovanen PT, Eklund KK: Cholesterol crystals activate the NLRP3 inflammasome in human macrophages: a novel link between cholesterol metabolism and inflammation. PLoS One 2010;5:e11765.

-9 Wen H, Ting JP, O'Neill LA: A role for the NLRP3 inflammasome in metabolic diseases--did Warburg miss inflammation? Nat Immunol 2012;13:352-357.

10 De Nardo D, Latz E: NLRP3 inflammasomes link inflammation and metabolic disease. Trends Immunol 2011;32:373-379.

-11 Mariathasan S, Weiss DS, Newton K, McBride J, O'Rourke K, Roose-Girma M, Lee WP, Weinrauch Y, Monack DM, Dixit VM: Cryopyrin activates the inflammasome in response to toxins and ATP. Nature 2006;440:228232.

-12 Halle A, Hornung V, Petzold GC, Stewart CR, Monks BG, Reinheckel T, Fitzgerald KA, Latz E, Moore KJ, Golenbock DT: The NALP3 inflammasome is involved in the innate immune response to amyloid-beta. Nat Immunol 2008;9:857-865.

13 Martinon F, Petrilli V, Mayor A, Tardivel A, Tschopp J: Gout-associated uric acid crystals activate the NALP3 inflammasome. Nature 2006;440:237-241.

-14 Liu W, Yin Y, Zhou Z, He M, Dai Y: OxLDL-induced IL-1 beta secretion promoting foam cells formation was mainly via CD36 mediated ROS production leading to NLRP3 inflammasome activation. Inflamm Res 2014;63:33-43.

15 Martinon F, Mayor A, Tschopp J: The inflammasomes: guardians of the body. Annu Rev Immunol 2009;27:229-265.

16 Shao BZ, Xu ZQ, Han BZ, Su DF, Liu C: NLRP3 inflammasome and its inhibitors: a review. Front Pharmacol 2015;6:262.

-17 Marchetti C, Chojnacki J, Toldo S, Mezzaroma E, Tranchida N, Rose SW, Federici M, Van Tassell BW, Zhang S, Abbate A: A novel pharmacologic inhibitor of the NLRP3 inflammasome limits myocardial injury after ischemia-reperfusion in the mouse. J Cardiovasc Pharmacol 2014;63:316-322.

-18 O'Connell RM, Rao DS, Baltimore D: microRNA regulation of inflammatory responses. Annu Rev Immunol 2012;30:295-312.

19 Nazari-Jahantigh M, Egea V, Schober A, Weber C: MicroRNA-specific regulatory mechanisms in atherosclerosis. J Mol Cell Cardiol 2015;89:35-41.

20 Zhang T, Tian F, Wang J, Jing J, Zhou SS, Chen YD: Atherosclerosis-Associated Endothelial Cell Apoptosis by MiR-429-Mediated Down Regulation of Bcl-2. Cell Physiol Biochem 2015;37:1421-1430.

-21 Yang Y, Yang L, Liang X, Zhu G: MicroRNA-155 Promotes Atherosclerosis Inflammation via Targeting SOCS1. Cell Physiol Biochem 2015;36:1371-1381. 


\section{Cellular Physiology Cell Physiol Biochem 2017;41:1555-1571 \begin{tabular}{l|l|l}
\hline DOI: 10.1159/000470822 & $\begin{array}{l}\text { C } 2017 \text { The Author(s). Published by S. Karger AG, Basel } \\
\text { www.karger.com/cpb }\end{array}$ \\
\hline
\end{tabular}}

22 Zhang T, Tian F, Wang J, Jing J, Zhou SS, Chen YD: Endothelial Cell Autophagy in Atherosclerosis is Regulated by miR-30-Mediated Translational Control of ATG6. Cell Physiol Biochem 2015;37:1369-1378.

23 Natarelli L, Schober A: MicroRNAs and the response to injury in atherosclerosis. Hamostaseologie 2015;35:142-150.

24 Chen T, Huang Z, Wang L, Wang Y, Wu F, Meng S, Wang C: MicroRNA-125a-5p partly regulates the inflammatory response, lipid uptake, and ORP9 expression in oxLDL-stimulated monocyte/macrophages. Cardiovasc Res 2009;83:131-139.

25 Wei Y, Nazari-Jahantigh M, Neth P, Weber C, Schober A: MicroRNA-126, -145, and -155: a therapeutic triad in atherosclerosis? Arterioscler Thromb Vasc Biol 2013;33:449-454.

-26 Wang JG, Williams JC, Davis BK, Jacobson K, Doerschuk CM, Ting JP, Mackman N: Monocytic microparticles activate endothelial cells in an IL-1beta-dependent manner. Blood 2011;118:2366-2374.

27 Ding Z, Liu S, Wang X, Dai Y, Khaidakov M, Deng X, Fan Y, Xiang D, Mehta JL: LOX-1, mtDNA damage, and NLRP3 inflammasome activation in macrophages: implications in atherogenesis. Cardiovasc Res 2014;103:619-628.

28 Meyre D, Froguel P, Horber FF, Kral JG: Comment on: Valette et al. Melanocortin-4 receptor mutations and polymorphisms do not affect weight loss after bariatric surgery. PLOS ONE 2012; 7(11):E48221. PLoS One 2014;9:e93324.

29 Sun B, Ji Z, Liao YP, Wang M, Wang X, Dong J, Chang CH, Li R, Zhang H, Nel AE, Xia T: Engineering an effective immune adjuvant by designed control of shape and crystallinity of aluminum oxyhydroxide nanoparticles. ACS Nano 2013;7:10834-10849.

30 Wang Y, Cao J, Fan Y, Xie Y, Xu Z, Yin Z, Gao L, Wang C: Artemisinin inhibits monocyte adhesion to HUVECs through the NF-kappaB and MAPK pathways in vitro. Int J Mol Med 2016;37:1567-1575.

-31 Hecker A, Kullmar M, Wilker S, Richter K, Zakrzewicz A, Atanasova S, Mathes V, Timm T, Lerner S, Klein J, Kaufmann A, Bauer S, Padberg W, Kummer W, Janciauskiene S, Fronius M, Schweda EK, Lochnit G, Grau V: Phosphocholine-Modified Macromolecules and Canonical Nicotinic Agonists Inhibit ATP-Induced IL-1beta Release. J Immunol 2015;195:2325-2334.

-32 Meng S, Cao J, Zhang X, Fan Y, Fang L, Wang C, Lv Z, Fu D, Li Y: Downregulation of microRNA-130a contributes to endothelial progenitor cell dysfunction in diabetic patients via its target Runx3. PLoS One 2013;8:e68611.

33 Krichevsky AM, King KS, Donahue CP, Khrapko K, Kosik KS: A microRNA array reveals extensive regulation of microRNAs during brain development. RNA 2003;9:1274-1281.

34 Li H, Ambade A, Re F: Cutting edge: Necrosis activates the NLRP3 inflammasome. J Immunol 2009;183:1528-1532.

-35 Deguchi JO, Aikawa E, Libby P, Vachon JR, Inada M, Krane SM, Whittaker P, Aikawa M: Matrix metalloproteinase-13/collagenase-3 deletion promotes collagen accumulation and organization in mouse atherosclerotic plaques. Circulation 2005;112:2708-2715.

-36 Bazzoni F, Rossato M, Fabbri M, Gaudiosi D, Mirolo M, Mori L, Tamassia N, Mantovani A, Cassatella MA, Locati M: Induction and regulatory function of miR-9 in human monocytes and neutrophils exposed to proinflammatory signals. Proc Natl Acad Sci U S A 2009;106:5282-5287.

-37 Nie K, Gomez M, Landgraf P, Garcia JF, Liu Y, Tan LH, Chadburn A, Tuschl T, Knowles DM, Tam W: MicroRNAmediated down-regulation of PRDM1/Blimp-1 in Hodgkin/Reed-Sternberg cells: a potential pathogenetic lesion in Hodgkin lymphomas. Am J Pathol 2008;173:242-252.

-38 Xu J, Hu G, Lu M, Xiong Y, Li Q Chang CC, Song B, Chang T, Li B: MiR-9 reduces human acyl-coenzyme A:cholesterol acyltransferase-1 to decrease THP-1 macrophage-derived foam cell formation. Acta Biochim Biophys Sin (Shanghai) 2013;45:953-962.

-39 Krichevsky AM, Sonntag KC, Isacson O, Kosik KS: Specific microRNAs modulate embryonic stem cellderived neurogenesis. Stem Cells 2006;24:857-864.

40 Jeyabal P, Thandavarayan RA, Joladarashi D, Suresh Babu S, Krishnamurthy S, Bhimaraj A, Youker KA, Kishore R, Krishnamurthy P: MicroRNA-9 inhibits hyperglycemia-induced pyroptosis in human ventricular cardiomyocytes by targeting ELAVL1. Biochem Biophys Res Commun 2016;471:423-429.

41 Jones SW, Watkins G, Le Good N, Roberts S, Murphy CL, Brockbank SM, Needham MR, Read SJ, Newham $\mathrm{P}$ : The identification of differentially expressed microRNA in osteoarthritic tissue that modulate the production of TNF-alpha and MMP13. Osteoarthritis Cartilage 2009;17:464-472.

$\$ 42$ Medzhitov R: Toll-like receptors and innate immunity. Nat Rev Immunol 2001;1:135-145. 


\section{Cellular Physiology Cell Physiol Biochem 2017;41:1555-1571

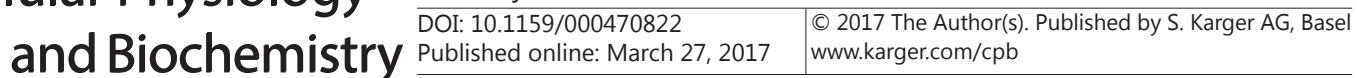 \\ Wang et al.: MicroRNA-9 Inhibits NLRP3 Inflammasome Activation}

43 Sheedy FJ, Grebe A, Rayner KJ, Kalantari P, Ramkhelawon B, Carpenter SB, Becker CE, Ediriweera HN, Mullick AE, Golenbock DT, Stuart LM, Latz E, Fitzgerald KA, Moore KJ: CD36 coordinates NLRP3 inflammasome activation by facilitating intracellular nucleation of soluble ligands into particulate ligands in sterile inflammation. Nat Immunol 2013;14:812-820.

44 Abderrazak A, Couchie D, Mahmood DF, Elhage R, Vindis C, Laffargue M, Mateo V, Buchele B, Ayala MR, El Gaafary M, Syrovets T, Slimane MN, Friguet B, Fulop T, Simmet T, El Hadri K, Rouis M: Anti-inflammatory and antiatherogenic effects of the NLRP3 inflammasome inhibitor arglabin in ApoE2.Ki mice fed a high-fat diet. Circulation 2015;131:1061-1070.

45 Usui F, Shirasuna K, Kimura H, Tatsumi K, Kawashima A, Karasawa T, Hida S, Sagara J, Taniguchi S, Takahashi M: Critical role of caspase-1 in vascular inflammation and development of atherosclerosis in Western diet-fed apolipoprotein E-deficient mice. Biochem Biophys Res Commun 2012;425:162-168.

46 Li S, Fan Q, He S, Tang T, Liao Y, Xie J: MicroRNA-21 negatively regulates Treg cells through a TGF-beta1/ Smad-independent pathway in patients with coronary heart disease. Cell Physiol Biochem 2015;37:866878.

47 Zuo K, Zhi K, Zhang X, Lu C, Wang S, Li M, He B: A dysregulated microRNA-26a/EphA2 axis impairs endothelial progenitor cell function via the p38 MAPK/VEGF pathway. Cell Physiol Biochem 2015;35:477488.

48 Zhao J, Lin Q, Kim KJ, Dardashti FD, Kim J, He F, Sun Y: Ngn1 inhibits astrogliogenesis through induction of miR-9 during neuronal fate specification. Elife 2015;4:e06885.

49 Zhang C, Zhao YX, Zhang YH, Zhu L, Deng BP, Zhou ZL, Li SY, Lu XT, Song LL, Lei XM, Tang WB, Wang N, Pan CM, Song HD, Liu CX, Dong B, Zhang Y, Cao Y: Angiotensin-converting enzyme 2 attenuates atherosclerotic lesions by targeting vascular cells. Proc Natl Acad Sci U S A 2010;107:15886-15891.

50 O'Shea JJ, Plenge R: JAK and STAT signaling molecules in immunoregulation and immune-mediated disease. Immunity 2012;36:542-550.

51 Maziere C, Alimardani G, Dantin F, Dubois F, Conte MA, Maziere JC: Oxidized LDL activates STAT1 and STAT3 transcription factors: possible involvement of reactive oxygen species. FEBS Lett 1999;448:49-52.

$\$ 52$ Maziere C, Conte MA, Maziere JC: Activation of JAK2 by the oxidative stress generated with oxidized lowdensity lipoprotein. Free Radic Biol Med 2001;31:1334-1340.

53 Capiralla H, Vingtdeux V, Zhao H, Sankowski R, Al-Abed Y, Davies P, Marambaud P: Resveratrol mitigates lipopolysaccharide- and Abeta-mediated microglial inflammation by inhibiting the TLR4/NF-kappaB/STAT signaling cascade. J Neurochem 2012;120:461-472.

-54 Lu B, Antoine DJ, Kwan K, Lundback P, Wahamaa H, Schierbeck H, Robinson M, Van Zoelen MA, Yang H, Li J, Erlandsson-Harris H, Chavan SS, Wang H, Andersson U, Tracey KJ: JAK/STAT1 signaling promotes HMGB1 hyperacetylation and nuclear translocation. Proc Natl Acad Sci U S A 2014;111:3068-3073.

-55 Guarda G, Braun M, Staehli F, Tardivel A, Mattmann C, Forster I, Farlik M, Decker T, Du Pasquier RA, Romero P, Tschopp J: Type I interferon inhibits interleukin-1 production and inflammasome activation. Immunity 2011;34:213-223. 